Article

\title{
Drug Solubility Enhancement through the Preparation of Multicomponent Organic Materials: Eutectics of Lovastatin with Carboxylic Acids
}

\author{
Andrea Mariela Araya-Sibaja 1,2,3 (), José Roberto Vega-Baudrit 1,4, Teodolito Guillén-Girón ${ }^{2}$, \\ Mirtha Navarro-Hoyos ${ }^{3}(1)$ and Silvia Lucia Cuffini ${ }^{5, *}$ \\ 1 Laboratorio Nacional de Nanotecnología LANOTEC-CeNAT-CONARE, Pavas 1174-1200, San José, \\ Costa Rica; andrea.araya@gmail.com (A.M.A.-S.); jvegab@gmail.com (J.R.V.-B.) \\ 2 Centro de Investigación y Extensión en Materiales, Escuela de Ciencia e Ingeniería de los Materiales, \\ Tecnológico de Costa Rica, Cartago 159-7050, Costa Rica; tguillen@itcr.ac.cr \\ 3 Escuela de Química, Universidad de Costa Rica, San Pedro de Montes de Oca, San José 2060, Costa Rica; \\ mnavarro@codeti.org \\ 4 Laboratorio de Investigación y Tecnología de Polímeros POLIUNA, Escuela de Química, \\ Universidad Nacional de Costa Rica, Heredia 86-3000, Costa Rica \\ 5 Instituto de Ciência e Técnica, Universidade Federal de São Paulo, São José dos Campos, \\ CEP: 12.223-201 São Paulo, Brazil \\ * Correspondence: scuffini@unifesp.br; Tel.: +55-(12)-3901-4440
}

Received: 9 February 2019; Accepted: 26 February 2019; Published: 9 March 2019

check for updates

\begin{abstract}
Lovastatin (LOV) is a drug used to treat hypercholesterolemia. Recent studies have identified its antioxidant effects and potential use in the treatment of some types of cancer. However, the low bioavailability related to its poor water solubility limits its use in solid oral dosage forms. Therefore, to improve the solubility of LOV three eutectic systems of LOV with the carboxylic acids benzoic (BEN), salicylic (SAL) and cinnamic (CIN) were obtained. Both binary phase and Tammann diagrams were constructed using differential scanning calorimetry (DSC) data of mixtures prepared from 0.1 to 1.0 molar ratios. Binary mixtures and eutectics were prepared by liquid-assisted grinding. The eutectics were further characterized by DSC and powder X-ray diffraction (PXRD), Fourier-transform infrared spectroscopy (FT-IR) and scanning electron microscopy (SEM). The LOV-BEN, LOV-SAL and LOV-CIN system formed a eutectic at an LOV mole fraction of 0.19, 0.60 and 0.14 , respectively. The systems exhibited improvements in LOV solubility, becoming more soluble by five-fold in the LOV-SAL system and approximately four-fold in the other two systems. Considering that the solubility enhancements and the carboxylic acids used are generally recognized as safe by the U.S. Food and Drug Administration (FDA), the LOV eutectic systems are promising materials to be used in a solubility enhancement strategy for pharmaceutical product formulation.
\end{abstract}

Keywords: lovastatin; eutectic mixtures; carboxylic acids; multicomponent organic materials; GRAS substances

\section{Introduction}

Eutectic mixtures are multicomponent organic materials formed by two or more crystalline solids that are immiscible in the solid state and miscible in the liquid state [1,2]. Their formation occurs via noncovalent forces [3,4], mainly hydrogen bonding, ionic and van der Waals forces, and aromatic interactions [4]. In general, the melting temperature of the eutectic is lower than the melting temperatures of their parent components [5]. These systems can be considered as intimately physically blended, with high thermodynamic functions, such as free energy, enthalpy and entropy [6], 
which provide both solubility and dissolution enhancements [7,8]. Furthermore, highly water-soluble carriers and excipients can favorably impact the wettability of the drug, conferring bioavailability improvements [8,9]. Finally, the increased surface area of the components also contributes in dissolution rate increments similar to what occurs with amorphous solids and solid dispersions $[6,7,9]$.

Although organic eutectics possess differences in critical properties related to product performance, like solubility, stability, and bioavailability, they have been relatively unexplored compared to salts and cocrystals [10,11]. In the past few years, the interest in eutectics has increased considerably for pharmaceutical applications, because the use of eutectics in pharmaceutical formulations is quite advantageous compared to other strategies for the following reasons: (1) eutectics are inexpensive, easier to produce and scale up $[9,12]$; (2) they are not considered new chemical entities [9] or a new crystal form [13] (e.g., cocrystal) and consequently do not require clinical trials; and (3) in eutectic systems, the drug and coformer exist as crystalline compounds, which are highly stable compared to amorphous materials $[7,9,14]$.

Lovastatin (LOV) is widely used to control hypercholesterolemia and is a first-line treatment of coronary artery disease and atherosclerosis, which acts by inhibiting hydroxymethyl glutaryl coenzyme A (HMG-CoA) reductase [15]. Inhibitors of HMG-CoA have been shown to reduce oxidative stress [16], which is related to the mechanisms of initiation and development of several diseases [17], including cardiovascular, neurological, endocrine and gastric disorders, and carcinogenesis and tumor progression $[17,18]$. In particular, it has been determined that LOV has antioxidant properties and shows an effect on oxidative stress [19]. Recent studies have shown that LOV can induce tumor cell apoptosis [20], inhibit the mevalonate pathway in breast cancer [21], is considered as a potential drug treatment in gastric cancer [22] and has been trialed in other cancer treatments [23]. Nevertheless, the low bioavailability of LOV related to its poor water solubility $[24,25]$ makes the formulation of this drug for oral administration quite challenging. Several efforts have been made to improve both the solubility and bioavailability of this drug through different approaches, including the synthesis of nanocrystals [26], nanomatrix-supported lipid bilayers [27], microspheres [28], self-nanoemulsifying drug delivery systems [29,30], methylated beta-cyclodextrin [31], solid lipid nanoparticles [32] and nanostructured lipid carriers [25]. Even though significant improvements in bioavailability have been achieved with these techniques, there are several drawbacks. In general, these strategies involve large quantities of organic solvents, additives and solubilizers that have toxic effects and increase the cost of production [26]. Limitations in drug loading and drug expulsion during storage [25] are other factors to be considered. Approaches based on particle-size reduction produce deficient mechanical properties of the material, as for example low flow and high adhesion. Furthermore, the resulting powders become extremely difficult to handle $[9,24]$. For an inclusion complex, a special molecular weight is required, and for emulsions, a minimum solubility of the drug in the oil phase is necessary $[9,24]$. Recently, solid dispersion approach has been successfully applied to improve the dissolution rate of LOV using acetylsalicylic acid as coformer [33], which has proved to be a simple strategy to overcome the poor water solubility of this drug.

Therefore, in this study, attempts have been made to produce eutectics of LOV with a series of water-soluble carboxylic acids. Benzoic acid (BEN), salicylic acid (SAL) and cinnamic acid (CIN) were used as coformers, which exhibit aqueous solubilities at $25^{\circ} \mathrm{C}$ of $3400 \mathrm{mg} / \mathrm{L}$ [34], $2240 \mathrm{mg} / \mathrm{L}$ [35] and $546 \mathrm{mg} / \mathrm{L}$, respectively. In addition, BEN as a food ingredient is not considered a hazard for human health [36], and SAL and CIN are permitted by the U.S. Food and Drug Administration (FDA) for direct addition to food as flavoring agents and adjuvants $[37,38]$. The chemical structures of LOV and the coformers are presented in Figure 1. To determine the exact eutectic composition, both binary phase and Tammann diagrams were constructed for the three systems, prepared using differential scanning calorimetry (DSC) data. The eutectics were characterized using X-ray powder diffraction (PXRD), Fourier-transform infrared spectroscopy (FT-IR) and scanning electron microscopy (SEM). Solubility assessments were applied to both the eutectic composition and a point outside of the eutectic composition for the three eutectic systems. 


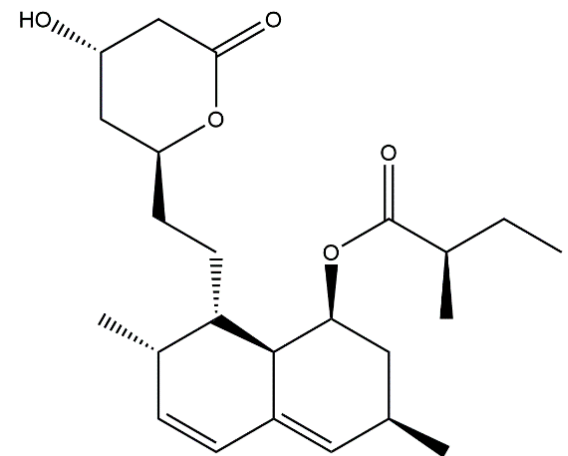

a) b)<smiles>O=C(O)c1ccccc1</smiles>

c)<smiles>O=C(O)c1ccccc1O</smiles>

d)<smiles>O=C(O)/C=C/c1ccccc1</smiles>

Figure 1. Chemical structure of (a) lovastatin (LOV), (b) benzoic acid (BEN), (c) salicylic acid (SAL) and (d) cinnamic acid (CIN).

\section{Materials and Methods}

\subsection{Materials}

The lovastatin (LOV) raw material was purchased from Valdequimica, Brazil (purity reported to be $>99 \%$ ) and used without further purification. Adipic acid (ADI, 99\% purity), citric acid (CIT, 99\% purity), and tartaric acid (TAR, 99\% purity) were acquired from Fischer Scientific (Hampton, NH, USA). Benzoic acid (BEN, 99\% purity), salicylic acid (SAL, 99\% purity) and cinnamic acid (CIN, 99\% purity) were purchased from Merck (Darmstadt, Hesse, Germany), Mallinckrodt (Phillipsburg, NY, USA) and Sigma-Aldrich (Saint Louis, MO, USA), respectively. Lovastatin pharmaceutical secondary standard traceable to USP and PhEur Fluka brand used in the HPLC quantification studies was purchased from Sigma-Aldrich. All solvents were HPLC/UV grade, and water was purified using a Millipore system filtered through a Millipore $0.22 \mu \mathrm{m}$ Millipak ${ }^{\mathrm{TM}} 40$ membrane.

\subsection{Lovastatin Eutectic Mixture Screening}

Lovastatin and the carboxylic acids adipic (ADI), citric (CIT) tartaric (TAR), BEN, SAL and CIN were individually and accurately weighed to obtain $50 \mathrm{mg}$ of a binary mixture in a 1:1 molar ratio. The binary mixtures were ground together using liquid (ethanol $20 \mu \mathrm{L}$ ) assisted grinding technique. The obtained solids were evaluated in a DSC to determine the eutectic formation.

\section{3. $L O V-B E N, L O V-S A L$ and LOV-CIN Eutectic Systems}

\subsubsection{Determination of Mixture Composition at the Eutectic Point}

The composition at the eutectic point of LOV and the selected carboxylic acid (BEN, SAL or CIN) was obtained by the construction of Tammann and binary phase diagrams. The diagrams were prepared according to the literature [11,39], considering the recommendations given by Rycerz (2013) for the use of DSC data [39]. Different molar ratios of LOV and the selected carboxylic acids (e.g., 0:1, 0.1:0.9, 0.2:0.8, 0.3:0.7, 0.4:0.6, 0.5:0.5, 0.6:0.4, 0.7:0.3, 0.8:0.2, and 0.9:0.1) were prepared as described in the previous section. Briefly, the appropriate amount of each component to obtain $50 \mathrm{mg}$ of the desired binary mixture was placed in a glass mortar and pestle. The mixture was then ground for $10 \mathrm{~min}$, assisted by $20 \mu \mathrm{L}$ of ethanol. Then, $2 \mathrm{mg}$ of the obtained solid was placed into an aluminum crucible and analyzed from 40 to $200{ }^{\circ} \mathrm{C}$ at a heating rate of $10^{\circ} \mathrm{C} / \mathrm{min}$ using the DSC equipment described below. Higher and lower heating rates (e.g., $5^{\circ} \mathrm{C} / \mathrm{min}$ and $50{ }^{\circ} \mathrm{C} / \mathrm{min}$ ) were used to improve thermal events and avoid peak overlap. In the phase diagram construction, the onset temperature of the first endothermic event was used as the solidus point and the peak of the second endothermic event was 
considered the liquidus point. In the case of the Tammann diagrams, the onset temperature and the enthalpy of fusion of the first endothermic event were used. The analyses of data were performed using TA Instruments-Waters LLC Universal Analysis 2000 software (version 4.5A, New Castle, DE, USA, 2016). Each analysis was performed in triplicate.

\subsubsection{Preparation of Bulk Mixtures at the Eutectic Composition}

To perform solid-state characterization and solubility assessments, the LOV-BEN, LOV-SAL and LOV-CIN eutectic systems were prepared in a larger amount in their respective eutectic composition. The same method as described in Section 2.2 was used for the scale-up. In short, the following amounts were accurately weighed: for the LOV-BEN system, $438 \mathrm{mg}$ LOV and $563.7 \mathrm{mg}$ BEN (43.7:56.3 wt\%); for the LOV-SAL system, $662 \mathrm{mg} \mathrm{LOV}$ and $339.0 \mathrm{mg}$ SAL (66.2:33.8 $\mathrm{wt} \%$ ); and for the LOV-CIN system, $308 \mathrm{LOV}$ and $692.9 \mathrm{CIN}(30.8: 69.2 \mathrm{wt} \%)$. The components of each system were mixed and homogenized for $20 \mathrm{~min}$ in a glass mortar and pestle using $400 \mu \mathrm{L}$ of ethanol as a catalyst. The obtained solids were dried at $60^{\circ} \mathrm{C}$ for $1 \mathrm{~h}$ and stored in a desiccator until further analysis.

\subsection{Characterization of the Eutectic Mixtures}

\subsubsection{Differential Scanning Calorimetry (DSC) Analysis}

Differential scanning calorimetry curves of the obtained solids were acquired using a DSC-Q200 (TA Instrument, New Castle, DE, USA) equipped with a TA Refrigerated Cooling System 90, using aluminum crucibles with approximately $2 \mathrm{mg}$ of the sample under a dynamic nitrogen atmosphere (50 $\mathrm{mL} / \mathrm{min}$ ) and a heating rate of $10{ }^{\circ} \mathrm{C} / \mathrm{min}$ in the temperature range from 40 to $200{ }^{\circ} \mathrm{C}$.

\subsubsection{Powder X-ray Diffraction (PXRD) Study}

Powder X-ray diffraction patterns were collected using a PANalytical Empyrean diffractometer equipped with a $\mathrm{Cu} \mathrm{K} \alpha$ source $(\lambda=1.5418 \AA)$ operated at $45 \mathrm{kV}$ and $40 \mathrm{~mA}$. Powder samples were placed onto a zero-background sample holder. The patterns were recorded over an angular range of $4-40^{\circ}(2 \theta)$ with a step size of $0.0130^{\circ}$ and a step time of $48 \mathrm{~s}$ using a silicon strip detector (PIXcel 1D). The diffractograms were obtained at ambient conditions.

\subsubsection{Fourier Transform Infrared (FT-IR)}

Fourier transform infrared spectra were recorded on a Thermo Scientific Nicolet 6700 FT-IR (Waltham, MA, USA) fitted with a diamond attenuated total reflectance (ATR) accessory. The samples were placed into the ATR cell without further preparation and analyzed in the range of $4000-600 \mathrm{~cm}^{-1}$, collecting 32 scans at a resolution of $4 \mathrm{~cm}^{-1}$.

\subsubsection{Scanning Electron Microscopy (SEM)}

Micrographs were obtained using a Hitachi Tabletop TM3000 scanning electron microscope (Fischeln, Krefeld, Germany) operated in the range of 5-30 kV. The samples were mounted on the sample holder using carbon double-sided adhesive tape. Vacuum was reached using an oil-free system consisting of a diaphragm pump for rough evacuation and a high-performance turbo-molecular pump for main pumping. 


\subsection{Physicochemical Study}

\subsubsection{Apparent Solubility}

The apparent solubilities of LOV and LOV eutectics were determined using the excess method in sodium lauryl sulphate (SLS) $0.25 \%(w / v)$ by oversupplying the solid to $1.5 \mathrm{~mL}$ of pre-equilibrated media at $37.5^{\circ} \mathrm{C}$ in microtubes. The resulting slurry was maintained at constant temperature and agitation using a BIOSAN TS-100C Thermo-Shaker (Riga, Latvia) for $24 \mathrm{~h}$. After this time, samples were centrifuged at $6000 \mathrm{rpm}$ for $10 \mathrm{~min}$ in a Thermo Scientific Sorvall ST 16R centrifuge maintaining the temperature of evaluation. The samples were filtered through a $0.45 \mu \mathrm{m}$ filter using a Sartorius stainless-steel syringe filter holder. The volume was adjusted accordingly to obtain a concentration within the analytical curve.

\subsubsection{Intrinsic Dissolution Rate (IDR) Determination}

Intrinsic dissolution rate determination was conducted using rotating disk method according to USP30-NF25 1087 Apparent dissolution test [40]. First, $100 \mathrm{mg}$ of the sample was compacted into $0.8 \mathrm{~cm}^{2}$ surface using a VIV TEK hydraulic press (Yangzhou, Jiangsu, China) with a manometer to 290 psi. Samples were analyzed in a SOTAX s7 dissolution test system, using $300 \mathrm{~mL}$ of SLS $0.25 \%(w / v)$ previously heated at $37 \pm 0.5^{\circ} \mathrm{C}$ as a dissolution medium and at a rotation speed of $75 \mathrm{rpm}$. Five mL of the samples were withdrawn at specific time intervals. To maintain a constant total volume a $5 \mathrm{~mL}$ aliquot of preheated fresh medium was replaced into the vessels. The sample aliquots were filtered using a $0.45 \mu \mathrm{m}$ membrane placed into a Sartorius stainless-steel syringe filter holder and injected without further dilutions. The sink conditions were maintained throughout the dissolution experiment.

\subsubsection{High-Performance Liquid Chromatography (HPLC) Analysis}

The drug concentration was determined using the HPLC pharmacopeial method [41]. A Dionex Ultimate 3000 HPLC system (Waltham, MA, USA), equipped with variable wavelength detector, pump, variable temperature compartment column and an autosampler was used. The mobile phase was composed of $65 \%$ acetonitrile and $35 \%$ water with $0.1 \%$ phosphoric acid, a flow rate of $1 \mathrm{~mL} / \mathrm{min}$, $50 \mu \mathrm{L}$ injection volume, detection at $238 \mathrm{~nm}$ in a Nucleosil 100-5C18 column $(250 \mathrm{~mm} \times 4.0 \mathrm{~mm}, 5 \mu \mathrm{m})$, and a temperature of $37.5^{\circ} \mathrm{C}$ were used.

A five-standards calibration curve of LOV concentrations ranging from 5 to $25 \mu \mathrm{g} / \mathrm{mL}$ was injected in the same sequence as the samples. The obtained regression coefficient $\left(R^{2}\right)$ was in all cases $\geq 0.99$. Each experiment was performed in triplicate, and average values were calculated.

\section{Results}

\subsection{Eutectic Mixture Screening}

Differential scanning calorimetry is the primary technique used to identify eutectic formation; hence, it was applied to screen the LOV and coformers/excipients in 1:1 binary mixture composition. Adipic acid, CIT and TAR were also evaluated and did not form eutectic mixtures with LOV. On the other hand, BEN, SAL and CIN were able to form eutectic mixtures with LOV. As expected for eutectic mixtures, a unique endothermic event is observed in Figure 2a-c corresponding to LOV-BEN, LOV-SAL and LOV-CIN eutectic formation, respectively. The thermograms show a significant reduction in the melting temperature of the eutectic systems compared to the melting temperatures of the pure compounds, confirming eutectic formation. Therefore, the composition at the eutectic point, the solid-state characterization and the solubility analyses were performed on the LOV-BEN, LOV-SAL and LOV-CIN systems. 


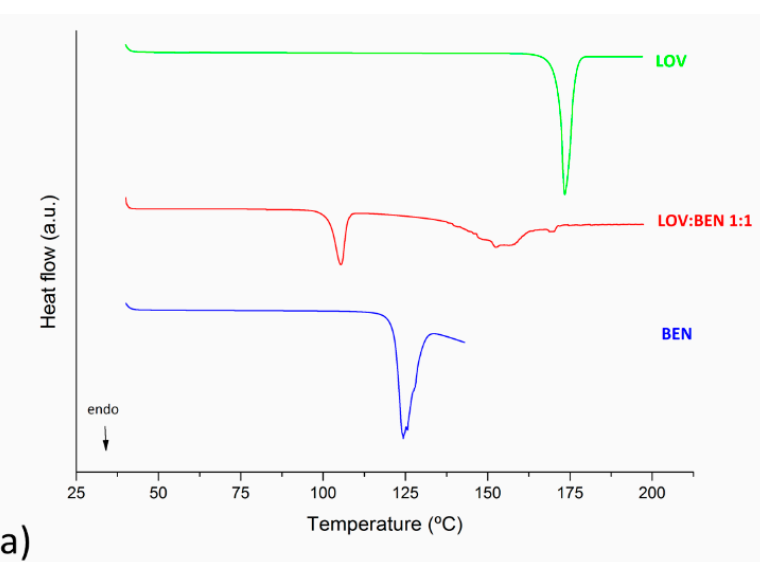

(a)

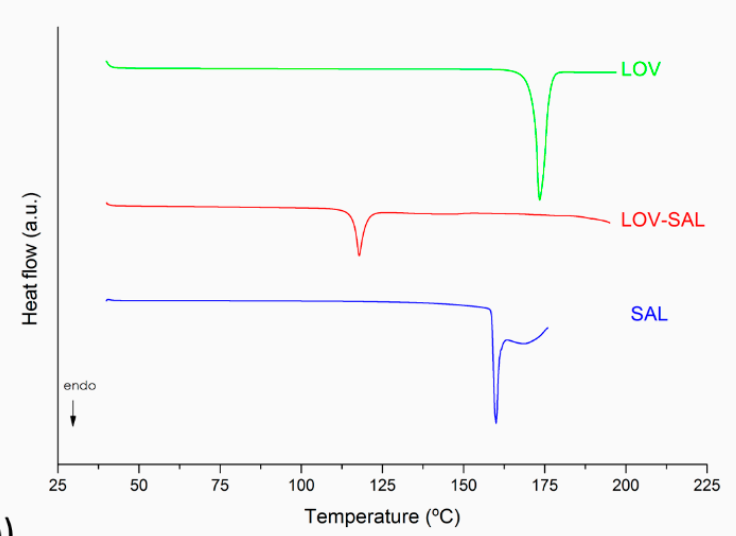

(b)

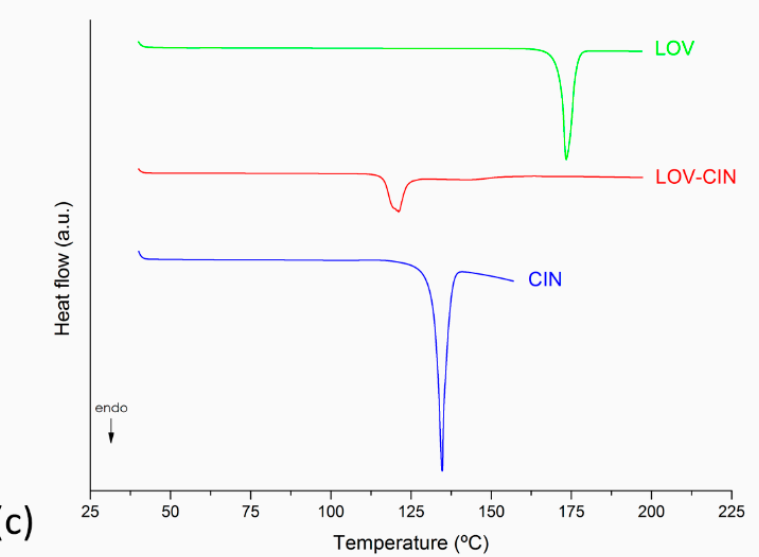

Figure 2. Differential scanning calorimetry (DSC) curves obtained in the eutectic mixture screening of LOV and selected carboxylic acids: (a) LOV, BEN and LOV-BEN, (b) LOV, SAL and LOV-SAL and (c) LOV, CIN and LOV-CIN.

\subsection{Binary Phase and Tammann Diagrams}

Suitable determination of eutectic composition requires the construction of both the binary and Tammann diagrams [39]. In the phase diagram, the melting temperature of the eutectic mixture (solidus point) and the excess component (liquidus point) is plotted as a function of the mole fraction of LOV. On the other hand, the Tammann diagram shows the systematic dependence of molar enthalpy associated with the eutectic effect on the mole fraction [39]. These diagrams were constructed for the three eutectic systems, LOV-BEN, LOV-SAL and LOV-CIN. The eutectic phase diagrams were drawn using the melting endotherms of the binary mixtures obtained in variable molar ratios of LOV:coformer: 0:1, 0.1:0.9, 0.2:0.8, 0.3:0.7, 0.4:0.6, 0.5:0.5, 0.6:0.4, 0.7:0.3, 0.8:0.2, 0.9:0.1, and 1:0 mol/mol. Figures $3 a, b, 4 a, b$ and $5 a, b$ present the DSC curves used to generate the diagrams (a) and the eutectic 
phase diagrams obtained (b) for the LOV-BEN, LOV-SAL and LOV-CIN systems, respectively. The Tammann diagrams for the LOV-BEN, LOV-SAL and LOV-CIN eutectic mixtures are shown in Figures $3 c, 4 c$ and $5 c$, respectively, where the intercept of the linear curve indicates the mole fraction of drug:coformer in the eutectic composition. Therefore, from the constructed phase and Tammann diagrams, the molar ratios of LOV-BEN, LOV-SAL and LOV-CIN were 0.19:0.81, 0.40:0.60 and 0.14:0.86, respectively.

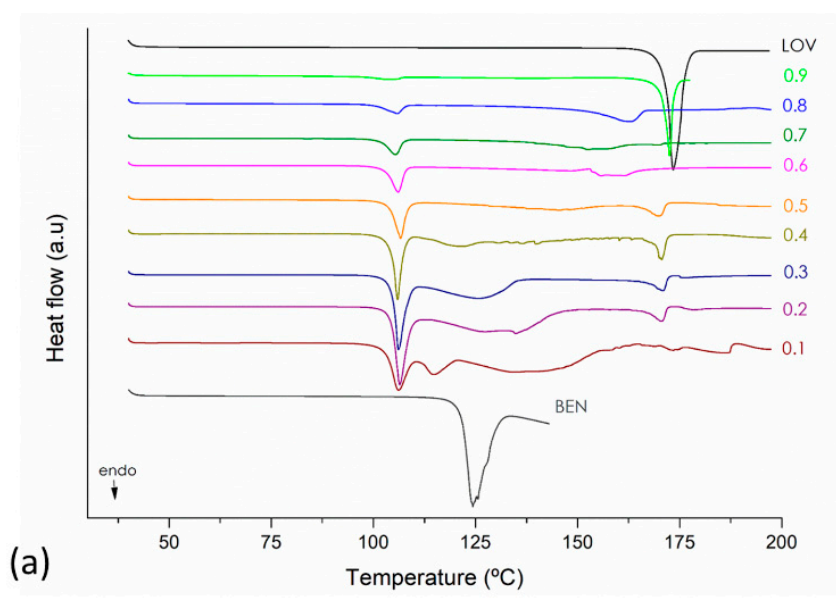

(a)
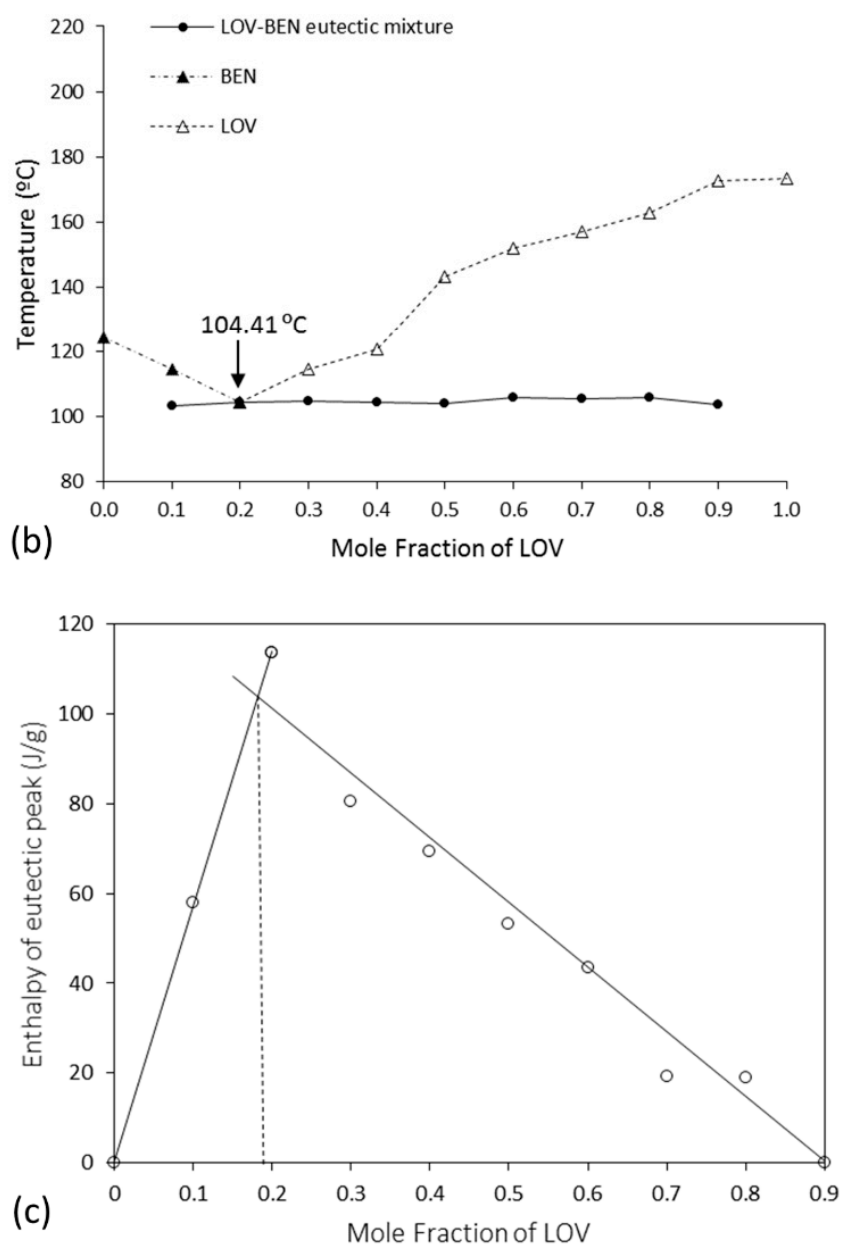

Figure 3. (a) DSC curves used to construct $(\mathbf{b})$ the eutectic phase diagrams $(\mathbf{\Lambda})$ where $(\Delta)$ represents the variable liquidus line; $(\bullet)$ represents the solidus line. (c) The Tammann diagram of LOV-BEN of eutectic mixture. 
(a)
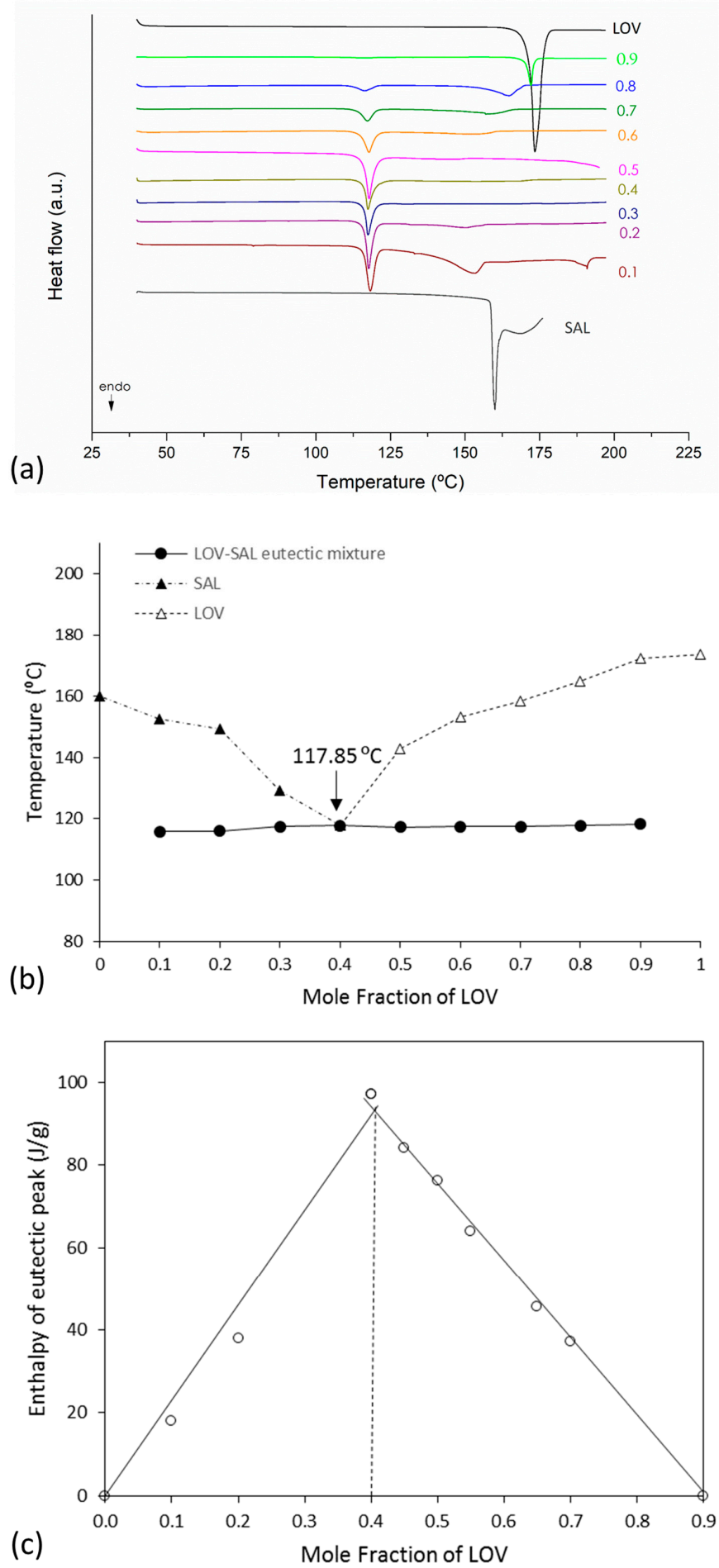

Figure 4. (a) DSC curves used to construct (b) the eutectic phase diagram $(\mathbf{\Delta})$ where $(\Delta)$ represents the variable liquidus line; $(\bullet)$ represents the solidus line. (c) The Tammann diagram of LOV-SAL system. 

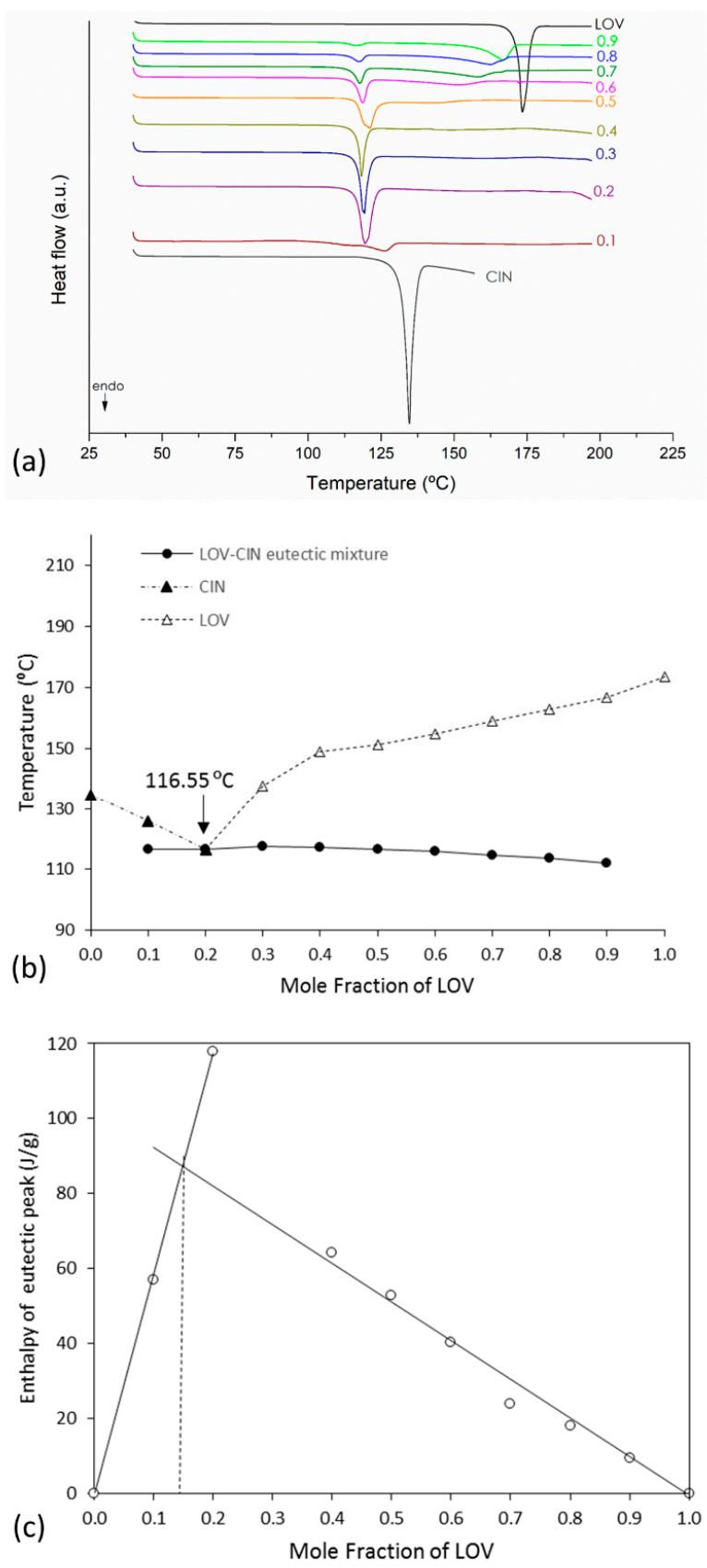

Figure 5. (a) DSC curves used to construct (b) the eutectic phase diagram $(\mathbf{\Delta})$ where $(\Delta)$ represents the variable liquidus line; $(\bullet)$ represents the solidus line. (c) The Tammann diagram of LOV-CIN system.

\subsection{Solid-State Characterization of LOV Eutectic Systems}

One of the requirements for eutectic mixture formation is that the components forming the mixture should have moieties that can interact to form noncovalent interactions [4], with a major presence of electrostatic interactions [42]. In the case of LOV and the selected carboxylic acids (Figure 1), the main interaction should occur between the carbonyl and hydroxyl groups present in both LOV and the carboxylic acids used. However, according to Cherukuvada and Nangia (2014) a new chemical entity is formed when the adhesive interactions (i.e., attractive forces between different molecules) are higher than the cohesive (i.e., intermolecular forces occurring between the same molecule) [6]. In the absence of structural rules to determine whether the cohesive or adhesive forces will dominate ones over the others, the strategy is one of monitoring a new crystal phase or chemical entity formation through appropriate techniques. In this context, PXRD analyses determine crystal structure modifications 
and FT-IR is useful to follow changes in vibrational modes due to molecular interactions in the solid state [43]; because, it is quite sensible to crystal structure modifications, conformational rearrangements and chemical environment changes. Therefore, the purpose of this section is to show that no new chemical entity or crystalline phase has been prepared, only the eutectic systems of LOV-BEN, LOV-SAL and LOV-CIN.

\subsubsection{PXRD and FT-IR Analyses}

Powder X-ray diffraction and FT-IR analyses were performed to determine crystalline forms as a qualitative indicator of the crystallinity of the samples and interactions presented between LOV and the selected carboxylic acids. The rise of new or shifted bands in the FT-IR spectrum is indicative of molecular interactions in the solid state [14]. In addition, new reflections in the PXRD pattern that could not be assigned to any of the pure components is evidence of modifications in the crystal structure. Figure 6 presents the PXRD patterns and Figure S1 shows the FT-IR spectra of LOV, pure BEN, SAL and CIN and their respective eutectic mixtures, LOV-BEN (a), LOV-SAL (b) and LOV-CIN (c).

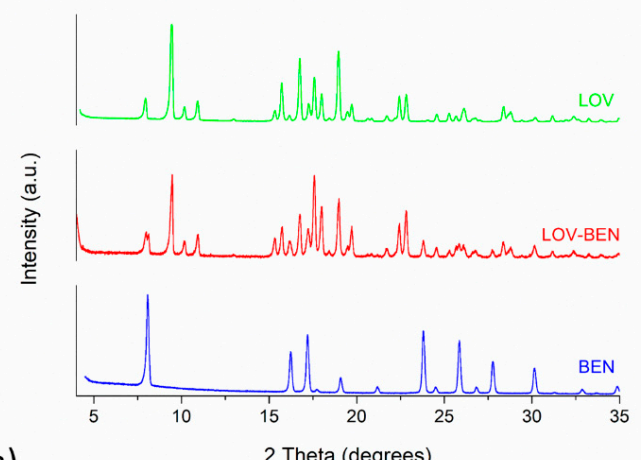

(a)

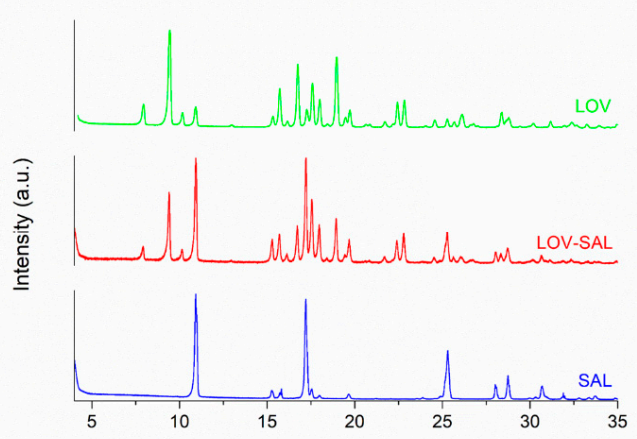

(b)

2 Theta (degrees)

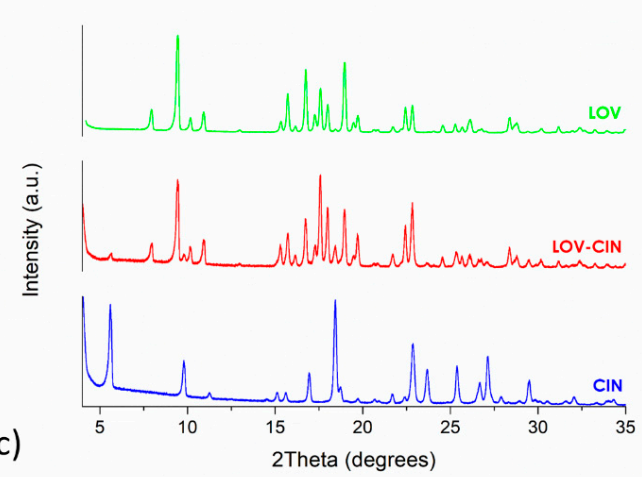

Figure 6. Powder X-ray diffraction (PXRD) patterns of LOV and selected carboxylic acids at the eutectic composition: (a) LOV, BEN and LOV-BEN, (b) LOV, SAL and LOV-SAL and (c) LOV, CIN and LOV-CIN. 
Although the PXRD patterns of LOV and the selected carboxylic acids possess several superimposed reflections, it is possible to distinguish at least two characteristic reflections. In the case of BEN, the reflections at $23.79^{\circ}$ and $27.76^{\circ}$ are distinctive and relatively intense. In the case of the LOV-BEN eutectic mixture, considering that the mole ratio at the eutectic composition is equivalent to $43.7: 56.3 \mathrm{wt} \%$ of the parent compounds, the reflection of both components is present in the PXRD pattern as shown in Figure 6a. It is also possible to observe the split peak approximately $8^{\circ}$ corresponding to the near reflections of LOV at $7.94^{\circ}$ and BEN at $8.07^{\circ}$.

Similarly, SAL presents two distinctive reflections at $28.01^{\circ}$ and $30.69^{\circ}$. However, the mole ratio of this eutectic system is equivalent to $66.2: 33.8 \mathrm{wt} \%$, with a higher content of LOV, and consequently, the PXRD pattern of the LOV-SAL eutectic mixture presented in Figure $6 \mathrm{~b}$ corresponds to mainly LOV reflections. The observed superimposed reflections of LOV and SAL at $10.92^{\circ}, 17.19^{\circ}$ and $25.30^{\circ}$ are increased in the diffractogram of the LOV-SAL system. Cinnamic, on the other hand, presents four characteristic reflections at $5.59^{\circ}, 9.80^{\circ}, 23.67^{\circ}$, and $27.14^{\circ}$. In this case, the composition of the LOV-CIN system is higher in CIN (69.2 $\mathrm{wt} \%)$, and the PXRD pattern possesses reflections of both components (Figure 6c). Finally, none of the three studied eutectic systems exhibited unassigned reflections, and therefore there is no evidence through the analyzed PXRD patterns of new crystalline phase formations.

The FT-IR of LOV shows characteristic peaks at $3535.81 \mathrm{~cm}^{-1}$ corresponding to the alcohol O-H stretching, at $1695.52 \mathrm{~cm}^{-1}$ consistent with the ester and lactone carbonyls $\mathrm{C}=\mathrm{O}$ stretching, and at $1214.52 \mathrm{~cm}^{-1}$ corresponding to a carbon-oxygen $\mathrm{C}-\mathrm{O}$ single bond asymmetric bend. The FT-IR for LOV-BEN, LOV-SAL and LOV-CIN eutectic systems show $\mathrm{O}-\mathrm{H}$ stretching peaks at 3537.81, 3536.03 and $3538.24 \mathrm{~cm}^{-1}, \mathrm{C}=\mathrm{O}$ stretching peaks at $1694.68,1695.55$ and $1694.99 \mathrm{~cm}^{-1}$, and $\mathrm{C}-\mathrm{O}$ asymmetric bending at $1214.95,1212.22$ and $1216.00 \mathrm{~cm}^{-1}$, respectively. Therefore, no major shifting in the LOV band positions in comparison to the eutectic mixtures suggests that there are no molecular interactions in the solid state. The combination of the results from the DSC, FT-IR and PXRD experiments confirmed that a eutectic mixture was formed in the systems.

\subsubsection{Scanning Electron Microscopy (SEM)}

Scanning electron microscopy images accurately contrast the morphological characteristics of LOV and the selected coformers, and the micrographs are shown in Figure 7: pure LOV (Figure 7a,b), pure BEN (Figure 7c), pure SAL (Figure 7e) and pure CIN (Figure 7g). LOV-BEN (Figure 7d), LOV-SAL (Figure $7 \mathrm{f}$ ) and LOV-CIN (Figure $7 \mathrm{~h}$ ) have significantly different morphologies compared to the individual components. A decrease in particle size related to the intrinsic characteristics of the grinding process is also evident in the three eutectic systems.

\subsection{Solubility Determinations of the Eutectic Systems}

To evaluate the impact of eutectic mixture formation on drug solubility improvements, the apparent solubility was evaluated from two different compositions. The first was the eutectic composition obtained from the phase and Tammann diagrams. The second composition was selected by observation from the thermograms in Figures 3-5, corresponding to LOV-BEN, LOV-SAL and LOV-CIN, respectively. Therefore, the composition out of the eutectic point was selected from the DSC curves showing a unique endothermic event and a straight baseline. The compositions at the eutectic point were 0.19:0.81 for LOV-BEN, 0.40:0.60 for LOV-SAL and 0.14:0.86 for LOV-CIN. In addition, the selected compositions outside of the eutectic point were 0.70:0.30 for LOV-BEN, 0.58:0.42 for LOV-SAL and 0.70:0.30 for LOV-CIN. Table 1 presents the results obtained from the apparent solubility determinations. 

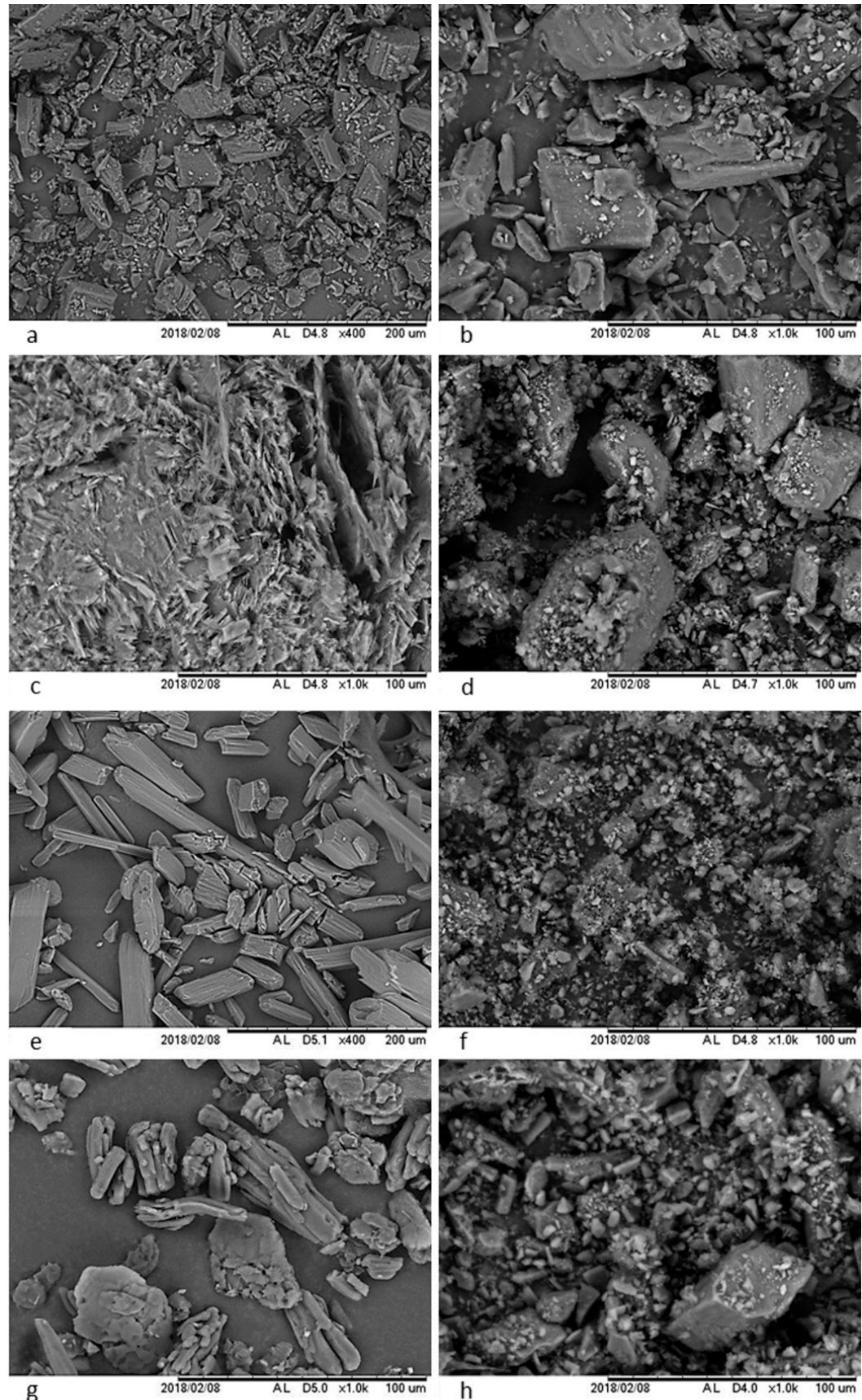

Figure 7. Micrographs of: (a,b) pure LOV) (c) pure BEN, (d) LOV-BEN eutectic mixture, (e) pure SAL, (f) LOV-SAL eutectic mixture, (g) pure CIN and (h) LOV-CIN eutectic mixture.

Table 1. Solubility determinations of pure LOV and lovastatin eutectic systems LOV-BEN, LOV-SAL and LOV-CIN at the eutectic composition and out of the eutectic composition.

\begin{tabular}{ccccc}
\hline System & $\begin{array}{c}\text { Composition at the } \\
\text { Eutectic Point }\end{array}$ & Solubility $(\mu \mathrm{g} / \mathrm{mL})$ & $\begin{array}{c}\text { Composition out of } \\
\text { the Eutectic Point }\end{array}$ & Solubility $(\mu \mathrm{g} / \mathbf{m L})$ \\
\hline LOV-BEN & $0.19: 0.81$ & $194 \pm 8$ & $0.70: 0.30$ & $147 \pm 3$ \\
\hline LOV-SAL & $0.40: 0.60$ & $259 \pm 4$ & $0.60: 0.40$ & $186 \pm 5$ \\
\hline LOV-CIN & $0.14: 0.86$ & $187 \pm 5$ & $0.30: 0.70$ & $163.7 \pm 0.2$ \\
\hline Pure LOV & & Solubility: $49 \pm 4 \mathrm{ug} / \mathrm{mL}$
\end{tabular}

a Eutectic composition obtained from both the Tammann and eutectic phase diagram; ${ }^{\mathrm{b}}$ Composition obtained directly by observation of the DSC curves. 
Eutectic materials were evaluated after solubility determinations by PXRD measurements, which are presented in Figure S2 (Supporting Information). The same PXRD pattern was observed from the eutectic before and after solubility evaluations. In the case of LOV-CIN eutectics, the disappearance of a reflection at $5.63^{\circ}$ ( $2 \theta$ position) related to the CIN raw material was observed. Therefore, the PXRD patterns confirmed that no dissociation of components had occurred in the three systems. Furthermore, there was no evidence of a new phase or cocrystal formation from the starting materials or any other crystal structure modification.

It is well known that bioavailability and the therapeutic effect of a drug depends on solubility and dissolution rate [44]. Moreover, IDR value has been demonstrated to be useful to correlate the in vivo drug dissolution dynamics [45]. Hence, the IDR was determined for the LOV-SAL eutectic system which showed to be the best solubility enhancer for LOV. Figure 8 shows a linear behavior in the intrinsic dissolution profile of pure LOV and the LOV-SAL system, with IDR values of $(0.0096 \pm 0.0004) \mathrm{mg} \mathrm{cm}^{-2} \mathrm{~min}^{-1}$ and $(0.0284 \pm 0.0002) \mathrm{mg} \mathrm{cm}^{-2} \mathrm{~min}^{-1}$, respectively, indicating that the LOV-SAL eutectic mixture showed in fact an important increment of solubility in respect to pure LOV.

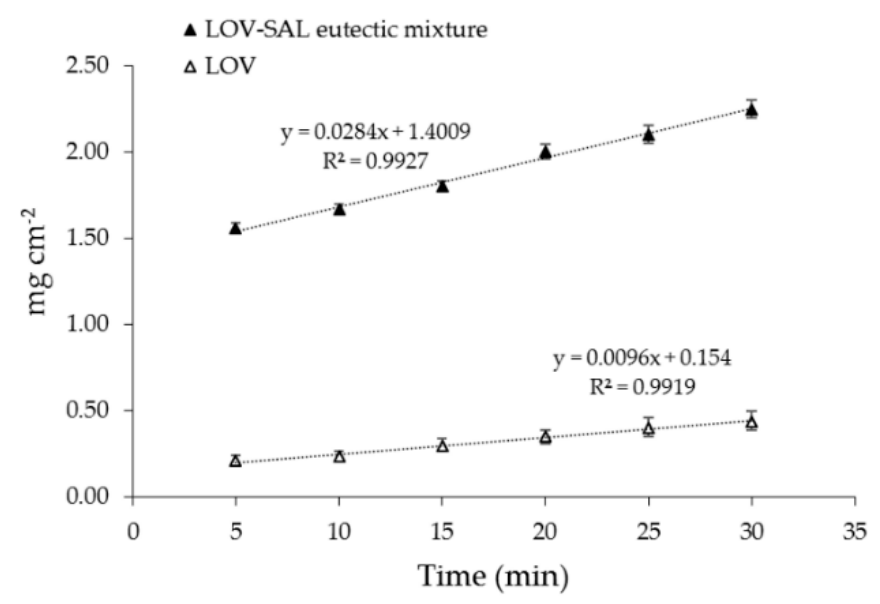

Figure 8. Intrinsic Dissolution Rate (IDR) profile of pure LOV and LOV-SAL eutectic mixture.

Although higher increments in LOV solubility were obtained using strategies based on nanotechnologies [27,31], it is important to stress that the eutectic formation approach is a reproducible and simple method with less expensive processing which produces an intermediary material during the formulation process. The latter conditions could be highly advantageous for pharmaceutical productions.

\section{Conclusions}

Binary eutectic mixtures of LOV with benzoic, salicylic and cinnamic carboxylic acids were able to be produced through liquid assisted grinding. Lovastatin showed improvements in solubility in all three systems. The increment of LOV solubility was found to be five-fold for the lovastatin-salicylic acid system and around four-fold for the other two systems. Further, PXRD analyses showed no dissociation of components from the eutectic system as well as no crystal structure modifications after solubility assessment. Considering the enhancement of LOV solubility, the use of carboxylic acids which are GRAS and EAFUS substances, and the accessibility of the method for the pharmaceutical industry, our results indicate that these lovastatin eutectic systems have promising applications in the preparation of new pharmaceutical formulations.

Supplementary Materials: The following are available online at http:/ /www.mdpi.com/1999-4923/11/3/112/s1, Figure S1: FT-IR spectra of LOV and selected carboxylic acids at the eutectic composition: (a) LOV, BEN and LOV-BEN, (b) LOV, SAL and LOV-SAL and (c) LOV, CIN and LOV-CIN. Figure S2: PXRD of LOV eutectics before and after solubility determinations: (a) LOV-BEN, (b) LOV-SAL and (c) LOV-CIN eutectic systems. 
Author Contributions: Conceptualization and methodology, A.M.A.-S. and S.L.C.; formal analysis, data curation and writing-original draft preparation, A.M.A.-S.; resources, J.R.V.-B., T.G.-G., M.N.-H.; writing-review and editing, J.R.V.-B., T.G.-G., M.N.-H., S.L.C.; supervision, S.L.C., T.G.-G.; project administration, J.R.V.-B., T.G.-G., M.N.-H.; funding acquisition, J.R.V.-B., T.G.-G., M.N.-H., A.M.A.-S.

Funding: This research was partially funded by FEES-CONARE, grant number 115B5662, the University of Costa Rica (UCR), grant number 115B7202, the Costa Rica Institute of Technology (TEC) and the National Laboratory of Nanotechnology (LANOTEC).

Acknowledgments: The authors thank the PINN program (PI-0132-15) from the Ministry of Science, Technology and Telecommunications of Costa Rica (MICITT), the scholarship program from the National Center for High Technology of Costa Rica (CeNAT) and the Postgraduate office of the TEC by the doctoral grant awarded to Andrea M. Araya-Sibaja. The authors are thankful to the Institutional Laboratory of Microscopy (LIM) of the TEC for the SEM images and the Research Center for Environmental Protection (CIPA) of the TEC for the HPLC analyses.

Conflicts of Interest: The authors declare no conflict of interest.

\section{References}

1. Jain, S.; Kurup, N. Formulation of Irbesartan by Microcrystal Technology for Enhancing the Solubility and Dissolution Properties. Int. J. Pharm. Sci. Nanotechnol. 2013, 6, 2064-2076.

2. Janssens, S.; Van den Mooter, G. Review: Physical chemistry of solid dispersions. J. Pharm. Pharmacol. 2009, 61, 1571-1586. [CrossRef] [PubMed]

3. Cherukuvada, S.; Guru Row, T.N. Comprehending the Formation of Eutectics and Cocrystals in Terms of Design and Their Structural Interrelationships. Cryst. Growth Des. 2014, 14, 4187-4198. [CrossRef]

4. Gala, U.; Chuong, M.C.; Varanasi, R.; Chauhan, H. Characterization and Comparison of Lidocaine-Tetracaine and Lidocaine-Camphor Eutectic Mixtures Based on Their Crystallization and Hydrogen-Bonding Abilities. Aaps Pharmscitech 2015, 16, 528-536. [CrossRef] [PubMed]

5. Jain, H.; Khomane, K.S.; Bansal, A.K. Implication of microstructure on the mechanical behaviour of an aspirin-paracetamol eutectic mixture. CrystEngComm 2014, 16, 8471-8478. [CrossRef]

6. Cherukuvada, S.; Nangia, A. Eutectics as improved pharmaceutical materials: Design, properties and characterization. Chem. Commun. 2014, 50, 906-923. [CrossRef] [PubMed]

7. Vippagunta, S.R.; Wang, Z.; Hornung, S.; Krill, S.L. Factors Affecting the Formation of Eutectic Solid Dispersions and Their Dissolution Behavior. J. Pharm. Sci. 2007, 96, 294-304. [CrossRef]

8. Hyun, S.-M.; Lee, B.J.; Abuzar, S.M.; Lee, S.; Joo, Y.; Hong, S.-H.; Kang, H.; Kwon, K.-A.; Velaga, S.; Hwang, S.-J. Preparation, characterization, and evaluation of celecoxib eutectic mixtures with adipic acid/saccharin for improvement of wettability and dissolution rate. Int. J. Pharm. 2019, 554, 61-71. [CrossRef]

9. Vasconcelos, T.; Sarmento, B.; Costa, P. Solid dispersions as strategy to improve oral bioavailability of poor water soluble drugs. Drug Discov. Today 2007, 12, 1068-1075. [CrossRef]

10. Stoler, E.; Warner, J.C. Non-Covalent derivatives: Cocrystals and eutectics. Molecules 2015, 20, 14833-14848. [CrossRef]

11. Chadha, K.; Karan, M.; Chadha, R.; Bhalla, Y.; Vasisht, K. Is Failure of Cocrystallization Actually a Failure? Eutectic Formation in Cocrystal Screening of Hesperetin. J. Pharm. Sci. 2017, 106, 2026-2036. [CrossRef] [PubMed]

12. Sathisaran, I.; Dalvi, S. Engineering Cocrystals of Poorly Water-Soluble Drugs to Enhance Dissolution in Aqueous Medium. Pharmaceutics 2018, 10, 108. [CrossRef] [PubMed]

13. International Conference on Harmonisation ICH Harmonised Tripartite Guideline Q6A. Test Procedures and Acceptance Criteria for New Drug Substance. Available online: https:/ / www.ich.org/fileadmin/Public_ Web_Site/ICH_Products/Guidelines/Quality/Q6A/Step4/Q6Astep4.pdf (accessed on 20 September 2018).

14. Avula, S.G.C.; Alexander, K.; Riga, A. Thermal analytical characterization of mixtures of antipsychotic drugs with various excipients for improved drug delivery. J. Therm. Anal. Calorim. 2016, 123, 1981-1992. [CrossRef]

15. Chen, C.-H.; Yang, J.-C.; Uang, Y.-S.; Lin, C.-J. Improved dissolution rate and oral bioavailability of lovastatin in red yeast rice products. Int. J. Pharm. 2013, 444, 18-24. [CrossRef] [PubMed]

16. Schiffrin, E.L. Antioxidants in hypertension and cardiovascular disease. Mol. Interv. 2010, 10, $354-362$. [CrossRef] [PubMed]

17. Sellés, A.N. Terapia antioxidante, estrés oxidativo y productos antioxidantes: Retos y oportunidades. Rev. Cuba. Salud Pública 2011, 37, 644-660. 
18. Sánchez, G.M. Especies reactivas del oxígeno y balance redox, parte I: Aspectos básicos y principales especies reactivas del oxígeno. Rev. Cuba. Farm. 2005, 39. Available online: http://scielo.sld.cu/scielo.php?pid= S0034-75152005000300009\&script=sci_arttext (accessed on 3 June 2018).

19. Kumar, S.; Srivastava, N.; Gomes, J. The effect of lovastatin on oxidative stress and antioxidant enzymes in hydrogen peroxide intoxicated rat. Food Chem. Toxicol. 2011, 49, 898-902. [CrossRef]

20. Niknejad, N.; Gorn-Hondermann, I.; Ma, L.; Zahr, S.; Johnson-Obeseki, S.; Corsten, M.; Dimitroulakos, J. Lovastatin-induced apoptosis is mediated by activating transcription factor 3 and enhanced in combination with salubrinal. Int. J. Cancer 2014, 134, 268-279. [CrossRef]

21. Koohestanimobarhan, S.; Salami, S.; Imeni, V.; Mohammadi, Z.; Bayat, O. Lipophilic statins antagonistically alter the major epithelial-to-mesenchymal transition signaling pathways in breast cancer stem-like cells via inhibition of the mevalonate pathway. J. Cell. Biochem. 2019, 120, 2515-2531. [CrossRef]

22. Zhang, L.; Kang, W.; Lu, X.; Ma, S.; Dong, L.; Zou, B. Weighted gene co-expression network analysis and connectivity map identifies lovastatin as a treatment option of gastric cancer by inhibiting HDAC2. Gene 2019, 681, 15-25. [CrossRef]

23. Johnson, M.D.; Woodard, A.; Okediji, E.J.; Toms, S.A.; Allen, G.S. Lovastatin is a potent inhibitor of meningioma cell proliferation: Evidence for inhibition of a mitogen associated protein kinase. J. Neurooncol. 2002, 56, 133-142. [CrossRef]

24. Patel, M.; Tekade, A.; Gattani, S.; Surana, S. Solubility enhancement of lovastatin by modified locust bean gum using solid dispersion techniques. AAPS PharmSciTech 2008, 9, 1262-1269. [CrossRef] [PubMed]

25. Zhou, J.; Zhou, D. Improvement of oral bioavailability of lovastatin by using nanostructured lipid carriers. Drug Des. Devel. Ther. 2015, 5269. [CrossRef] [PubMed]

26. Guo, M.; Fu, Q.; Wu, C.; Guo, Z.; Li, M.; Sun, J.; He, Z.; Yang, L. Rod shaped nanocrystals exhibit superior in vitro dissolution and in vivo bioavailability over spherical like nanocrystals: A case study of lovastatin. Colloids Surf. B Biointerfaces 2015, 128, 410-418. [CrossRef] [PubMed]

27. Zhang, Y.; Zhang, H.; Che, E.; Zhang, L.; Han, J.; Yang, Y.; Wang, S.; Zhang, M.; Gao, C. Development of novel mesoporous nanomatrix-supported lipid bilayers for oral sustained delivery of the water-insoluble drug, lovastatin. Colloids Surf. B Biointerfaces 2015, 128, 77-85. [CrossRef]

28. Guan, Q.; Chen, W.; Hu, X. Development of lovastatin-loaded poly(lactic acid) microspheres for sustained oral delivery: In vitro and ex vivo evaluation. Drug Des. Dev. Ther. 2015, 9, 791. [CrossRef]

29. Beg, S.; Sandhu, P.S.; Batra, R.S.; Khurana, R.K.; Singh, B. QbD-based systematic development of novel optimized solid self-nanoemulsifying drug delivery systems (SNEDDS) of lovastatin with enhanced biopharmaceutical performance. Drug Deliv. 2015, 22, 765-784. [CrossRef]

30. Rao, S.; Tan, A.; Boyd, B.J.; Prestidge, C.A. Synergistic role of self-emulsifying lipids and nanostructured porous silica particles in optimizing the oral delivery of lovastatin. Nanomedicine 2014, 9, 2745-2759. [CrossRef]

31. Süle, A.; Szente, L.; Csempesz, F. Enhancement of Drug Solubility in Supramolecular and Colloidal Systems. J. Pharm. Sci. 2009, 98, 484-494. [CrossRef]

32. Suresh, G.; Manjunath, K.; Venkateswarlu, V.; Satyanarayana, V. Preparation, characterization, and in vitro and in vivo evaluation of lovastatin solid lipid nanoparticles. AAPS PharmSciTech 2007, 8, E162-E170. [CrossRef] [PubMed]

33. Górniak, A.; Gajda, M.; Pluta, J.; Czapor-Irzabek, H.; Karolewicz, B. Thermal, spectroscopic and dissolution studies of lovastatin solid dispersions with acetylsalicylic acid. J. Therm. Anal. Calorim. 2016, 125, 777-784. [CrossRef]

34. PubChem Benzoic Acid Water Solubility. Available online: https://pubchem.ncbi.nlm.nih.gov/compound/ benzoic_acid\#section=Solubility (accessed on 5 November 2018).

35. PubChem Salicylic Acid Water Solubility. Available online: https://pubchem.ncbi.nlm.nih.gov/compound/ salicylic_acid\#section=Solubility (accessed on 5 November 2018).

36. FDA Benzoic Acid. Available online: http://wayback.archive-it.org/7993/20180124121624/https: //www.fda.gov/Food/IngredientsPackagingLabeling/GRAS/SCOGS/ucm260036.htm (accessed on 5 October 2018).

37. FDA Salicylic Acid. Available online: https://www.accessdata.fda.gov/scripts/fdcc/?set=FoodSubstances\& id=SALICYLICACID\&sort=Sortterm\&order=ASC\&startrow=1\&type=basic\&search=salicylicacid (accessed on 5 October 2018). 
38. FDA Cinnamic Acid. Available online: https://www.accessdata.fda.gov/scripts/fdcc/index.cfm?set= FoodSubstances\&id=CINNAMICACID\&sort=Sortterm\&order=ASC\&startrow=1\&type=basic\&search= cinnamicacid (accessed on 5 October 2018).

39. Rycerz, L. Practical remarks concerning phase diagrams determination on the basis of differential scanning calorimetry measurements. J. Therm. Anal. Calorim. 2013, 113, 231-238. [CrossRef]

40. USP $\langle 1087\rangle$ Apparent intrinsic dissolution-dissolution testing procedures for rotating disk and stationary disk. In The United State Pharmacopeia; United States Pharmacopeial Convention: Rockville, MD, USA, 2012; pp. 609-612.

41. USP. United State Pharmacopeia, 30th ed.; United States Pharmacopeial Convention: Rockville, MD, USA, 2007.

42. Figueirêdo, C.B.M.; Nadvorny, D.; de Medeiros Vieira, A.C.Q.; Soares Sobrinho, J.L.; Rolim Neto, P.J.; Lee, P.I.; de La Roca Soares, M.F. Enhancement of dissolution rate through eutectic mixture and solid solution of posaconazole and benznidazole. Int. J. Pharm. 2017, 525, 32-42. [CrossRef] [PubMed]

43. Bugay, D.E. Characterization of the solid-state: Spectroscopic techniques. Adv. Drug Deliv. Rev. 2001, 48, 43-65. [CrossRef]

44. Sanphui, P.; Goud, N.R.; Khandavilli, U.B.R.; Nangia, A. Fast Dissolving Curcumin Cocrystals. Cryst. Growth Des. 2011, 11, 4135-4145. [CrossRef]

45. Yu, L. Feasibility studies of utilizing disk intrinsic dissolution rate to classify drugs. Int. J. Pharm. 2004, 270, 221-227. [CrossRef]

(C) 2019 by the authors. Licensee MDPI, Basel, Switzerland. This article is an open access article distributed under the terms and conditions of the Creative Commons Attribution (CC BY) license (http:/ / creativecommons.org/licenses/by/4.0/). 